Submitted 06.03.2016. Approved 15.09.2016.

Evaluated by double blind review process.

DOI: http:///dx.doi/10.12660/joscmv9n2p17-27

\title{
AN INTEGRATED PRODUCTION, INVENTORY, WAREHOUSE LOCATION AND DISTRIBUTION MODEL
}

\author{
Lokendra Kumar Devangan \\ Masters in Industrial and Management Engineering from \\ the Indian Institute of Technology - Kanpur - Uttar Pradesh, India \\ lokendra2910@gmail.com
}

\begin{abstract}
This paper proposes an integrated production and distribution planning optimization model for multiple manufacturing locations, producing multiple products with deterministic demand at multiple locations. There are multiple modes of transport from plants to demand locations and warehouses. This study presents a model which allows decision makers to optimize plant production, transport and warehouse location simultaneously to fulfill the demands at customer locations within a multi-plant, multi-product, and multi-route supply chain system when the locations of the plants are already fixed. The proposed model is solved for sample problems and tested using real data from a cement manufacturing company in India. An analysis of the results suggests that this model can be used for various strategic and tactical production and planning decisions.
\end{abstract}

KEYWORDS: Supply chain management, integrated models, logistics, transshipment, warehouse location. 


\section{INTRODUCTION}

Extensive research has been performed to optimize production planning, inventory, warehouse location and vehicle routing, which have each been addressed as independent problems by several researchers (Fawcett \& Magnan, 2002). Ganeshan and Harrison (1995) classify supply chain functions into four categories - location, production, inventory and transportation. The independent modeling of supply chain functions has led to suboptimal solutions. There have generally been tradeoffs between computational efforts and optimality. Traditionally, independent optimization modeling of different stages of the supply chain has been pursued mainly due to limited computational resources.

With recent advances in terms of computational resources, studies featuring an integrated approach to modeling supply chain functions have been proposed (Erengüç, Simpson, and Vakharia 1999, and Kaur, Kanda, and Deshmukh, 2006). As manufacturing and economic conditions have become more dynamic, there has been a greater need to study supply chain functions using an integrated approach in terms of global supply chain operations. This approach is based on integrating the decision making related to various functions - location, production, inventory and distribution allocations - into a single optimization problem. The fundamental objective of this integrated approach is to optimize the variables for various functions simultaneously instead of sequentially as they have been optimized in the past. There are several advantages to integrated modeling such as reduced storage costs, less time spent on product customization and greater visibility in terms of demand.

This paper is organized as follows. The following section presents a brief review of the literature in the area of integrated supply chain optimization. Next section presents the proposed integrated supply chain optimization model in detail. After that, the results for problems of varying sizes including a problem with real data are discussed. The final section presents my conclusions and future avenues for research.

\section{LITERATURE REVIEW}

From the operational perspective, the issues of production scheduling, inventory policy and distribution routes have been modeled and optimized separately (Fawcett \& Magnan, 2002). Reviews of integrated models for production, inventory and distribution problems can be found in Erengüç et al. (1999). Chandra and Fisher (1994) compare the computational aspects of solving production and distribution problems separately as opposed to using a combined model. Dror and Ball (1987) and Chandra (1993) address the coordination of the inventory and distribution functions. Reviews of previous studies of multi-period international facility supply chain location problems have been provided by Canel and Khumawala (1997). They formulate a mixedinteger programming (MIP) model and solve it using a branch and bound design algorithm to decide where to place manufacturing facilities and how to determine production and shipping levels. Canel and Khumawala (2001) also develop a heuristic procedure for solving this MIP model considering a similar problem. Lei, Liu, Ruszczynski, and Park (2006) use a two-phase method to simultaneously solve the production, inventory, and routing problems. Fumero and Vercellis (1991) use Lagrangian relaxation (LR) to solve an MIP model for the integrated multi-period optimization of production and logistics operations. They compare the results produced by modeling separately and in an integrated fashion. To minimize costs in the integrated model, they use Lagrangian relaxation (LR) to permit the separation of the production and logistics functions. In this decoupled approach, the production and logistics problems are solved independently in two different optimization models. Pirkul and Jayaraman (1996) develop a cost minimization problem to model a multi-product, 3-echelon, plant capacity and warehouse location problem. Lagrangian relaxation (LR) is used to find the lower bound and then a heuristic method is used to solve the problem. Dasci and Verter (2001) consider approximated costs and demand to integrate the production and distribution functions. Closed form solutions are obtained to minimize the fixed costs of facility location, operations, and transport costs.

Arntzen, Brown, Harrison, and Trafton (1995) use a branch and bound algorithm to solve a global supply chain model at Digital Equipment Corporation for multiple products, facilities, echelons, time periods, and transport modes. They then solve it using branch and bound enumeration. Kumanan, Venkatesan, and Kumar (2007) develop two search techniques to minimize total production and distribution costs in a supply chain network. Camm et al. (1997) integrate distribution-location problems and a product sourcing problem as two supply chain problems at 
Proctor and Gamble. They use a geographical information system along with integer programming and network optimization models to solve the two subproblems. Dhaenens-Flipo and Finke (2001) model a network flow problem to minimize the cost of a supply chain within a multi-facility, multi-product and multi-period environment. Sabri and Beamon (2000) model stochastic demand, production and supply lead-times in a multi-objective, multi-product, and multi-echelon model to address strategic and operational planning. Lodree, Jang, and Klein (2004) propose the integration of customer waiting time with the production and distribution functions in the supply chain to determine the production rate and the sequence of vehicle shipments.

Garcia, Sánchez, Guerrero, Calle, and Smith (2004) and Silva et al. (2005) model an integrated optimization problem for perishable products. Garcia et al. (2004) consider a ready-mix concrete production and distribution problem, in which the selection of orders to be processed by a ready-mix concrete manufacturing plant has to be made, and orders have to have a fixed due date and need to be delivered directly to the customer site. Silva et al. (2005) also study a production and distribution problem with ready-mix concrete. Patel, Wei, Dessouky, Hao, and Pasakdee (2009) propose a model to minimize the total cost of distribution, storage, inventory and operations, and the determining of production levels appropriate to customer demand. They solve it using two heuristic methods and are able to provide a solution close to an optimal result which offers significant savings in runtime. Jolayemi (2010) develops two versions of a fully optimized model and a partially optimized model for production-distribution and transportation planning in three stage supply chain scenarios. Rong, Akkerman, and Grunow (2011) propose a mixed integer programming model for the integration of food quality for production and distribution in a food supply chain. They introduce the dynamics of food degradation by considering factors like storage temperature and transportation equipment in the proposed model. Larbi, Bekrar, Trentesaux, and Beldjilali (2012) formulate an integrated multiobjective supply chain model for an Algerian company in modular form to minimize the cost and time for quality control. Bashiri, Badri, and Talebi (2012) present a mathematical model addressing strategic and tactical planning in a multi-stage, multi-product production-distribution supply chain network and solve the optimization problem for illustrative numerical problems. Cóccola, Zamarripa, Méndez, and Espuña (2013) and Tang, Goetschalckx, and McGinnis (2013) propose an integrated production and distribution supply chain problem as a cost minimization problem applied to the chemical and aircraft manufacturing industries. Yu, Normasari, and Luong (2015) develop a cost minimization problem for small and medium size companies to decide how many plants and distribution centers to open and where to open them for a multi-stage supply chain network. Maleki and Cruz-Machado (2013) present a review of the integrated supply chain model and identify theoretical gaps in the integration model.

\section{THE INTEGRATED PRODUCTION AND DIS- TRIBUTION PLANNING MODEL}

\subsection{Problem statement}

In this study, we have developed an integrated production and distribution planning (IPDP) optimization model for a multi-product, multi-plant, multi-location and multi-echelon supply chain environment with multiple transport options including railways and roads. The manufacturing plants have the capacity to produce any product combination within the company's portfolio. The production capacity at the plant is shared among all the products which means that plants do not possess separate production lines for each type of product. In the literature, two types of costs are defined for any production plant. First we have fixed costs which include administrative costs and construction costs, etc. Second, we have variable input costs which depend on the quantity of the product manufactured. The production costs are made up of labor costs, the costs of procuring raw materials, packaging costs and costs related to the processing of the raw materials to produce the finished product. In this study, we assume that the unit production costs and unit packaging costs have been computed in such a way that they also account for the associated fixed costs of production and the packaging of the products at the plant. These costs vary from plant to plant due to local geopolitical and economic reasons. The distances between the manufacturing plants to the customer locations, between the plants to the warehouse, and between the warehouse and the customer locations are assumed to be known. Hence, the unit transport cost between two points is known which varies by the mode of transport. In this study, we assume that railways and roads are two of the types of transport available. Since the transportation capacity by any mode of transport from a plant to a warehouse or a 
customer location is bounded, we need to consider the type of transport in the optimization model. The warehouse inbound and outbound handling costs are dependent on the mode of transport which also makes this problem interesting. The implied unit sales price and taxes vary at each location.

The integrated profit maximization model proposed in this paper has been formulated as a mixed integer programming model which determines how to allocate production and distribution to fulfill demand at the customer location. The model also determines where to place subcontracted warehouses, and allows the user to decide the status of existing warehouses as to whether they should continue or end their operations. This model integrates the optimization of production, distribution, transport and warehouse location. The integrated production and distribution planning model is formulated as a mixed integer programming model to optimize production and distribution allocation within production constraints, obeying transport capacity and the given demand at various customer locations.

\subsection{Assumptions}

The assumptions for this integrated optimization model are as follows:

i. Integrated production and distribution optimization has been developed for a planning horizon period, which may be a month for example ii. The variable, production and packaging costs have been computed in such a way that they also account for the associated fixed costs of production and the packaging of the products at the plant.

iii. Each plant does not the capacity to produce every type of product.

iv. The total production capacity of a plant is shared among all the types of products and each product has its own limited capacity at each plant.

v. There is no inventory stored at the plants.

vi. Each plant can handle all types of packaging.

vii. The selling price for a product varies from customer to customer depending on what has been negotiated.

viii. Tax implications vary by customer location.

ix. A less than truckload (LTL) shipment is allowed without any penalty.

x. Customer demands can be fulfilled by supplying products directly from plants or warehouses.

\subsection{The formulation of the model}

The parameters and decision variables used to formulate the model are described below:

\section{Decision Variables}

$x_{p q i j r}$ : Production quantity of product $p$ with packaging type $q$ at plant $i$ to

supply warehouse $j$ using transport mode $r$

$v_{p q i k r}$ : Production quantity of product $p$ with packaging type $q$ at plant $i$ to

supply customer $k$ using transport mode $r$

$w_{p q j k r}$ : Quantity of product $p$ with packaging type $q$ at warehouse $j$ to supply

customer $k$ using transport mode $r$

$\delta_{j}:=\left\{\begin{array}{c}1 \text { if warehouse } j \text { will continue operations } \\ 0 \text { if warehouse } j \text { will end operations }\end{array}\right.$ 
Parameters

$P_{p i}:$ Unit production cost of product $p$ at plant $i$

$Q_{q i}$ : Unit packaging cost of packaging type $q$ at plant $i$

$R_{p q k}:$ Revenue from retailer $k$ for product $p$ and packaging $q$

$H_{j r}$ : Unit handling cost at warehouse $j$ for transport mode $r$

$\psi_{j}$ : Fixed setup cost of warehouse $j$

$E D_{p q k}:$ Excise duty at retailer $k$ for product $p$ and packaging $q$

$T_{i k r}$ : Unit transport cost between plant $i$ and retailer $k$ by transport mode $r$

$T_{i j r}$ : Unit transport cost between plant $i$ and warehouse $j$ by transport mode $r$

$T_{j k r}$ : Unit transport cost between warehouse $j$ and retailer $k$ by transport mode $r$

$C_{p i}$ : Production capacity of product $p$ at plant $i$

$C_{i}$ : Combined production capacity at plant $i$ for any product

$Z_{q i}$ : Packaging capacity of product $p$ at plant $i$

$S_{r i}$ : Maximum that can be sent from plant $i$ by transport mode $r$

$D_{p q k}$ : Maximum demand for product $p$ with packaging $q$ at customer location $k$

The profit maximizing objective function and constraints are expressed below:

Maximize

$$
\begin{aligned}
& \sum_{\mathrm{k}} \sum_{\mathrm{p}} \sum_{\mathrm{q}} \mathrm{R}_{\mathrm{pqk}}\left(\sum_{\mathrm{j}} \sum_{\mathrm{r}} \mathrm{w}_{\mathrm{pqjkr}}+\sum_{\mathrm{i}} \sum_{\mathrm{r}} \mathrm{v}_{\mathrm{pqikr}}\right)-\sum_{\mathrm{i}} \sum_{\mathrm{p}} \mathrm{P}_{\mathrm{pi}}\left(\sum_{\mathrm{q}} \sum_{\mathrm{j}} \sum_{\mathrm{r}} \mathrm{x}_{\mathrm{pqijr}}+\right. \\
& \left.\sum_{\mathrm{q}} \sum_{\mathrm{j}} \sum_{\mathrm{r}} \mathrm{v}_{\mathrm{pqikr}}\right)-\sum_{\mathrm{i}} \sum_{\mathrm{q}} \mathrm{Q}_{\mathrm{qi}}\left(\sum_{\mathrm{p}} \sum_{\mathrm{j}} \sum_{\mathrm{r}} \mathrm{x}_{\mathrm{pqijr}}+\sum_{\mathrm{p}} \sum_{\mathrm{j}} \sum_{\mathrm{r}} \mathrm{v}_{\mathrm{pqikr}}\right)- \\
& \sum_{\mathrm{j}} \sum_{\mathrm{r}} \mathrm{H}_{\mathrm{jr}}\left(\sum_{\mathrm{p}} \sum_{\mathrm{q}} \sum_{\mathrm{r}} \mathrm{x}_{\mathrm{pqijr}}+\sum_{\mathrm{p}} \sum_{\mathrm{q}} \sum_{\mathrm{k}} \mathrm{w}_{\mathrm{pqjkr}}\right)-\left(\sum_{\mathrm{i}} \sum_{\mathrm{j}} \sum_{\mathrm{r}} \mathrm{T}_{\mathrm{ijr}} \sum_{\mathrm{p}} \sum_{\mathrm{q}} \mathrm{x}_{\mathrm{pqijr}}+\right. \\
& \left.\sum_{\mathrm{i}} \sum_{\mathrm{k}} \sum_{\mathrm{r}} \mathrm{T}_{\mathrm{ikr}} \sum_{\mathrm{p}} \sum_{\mathrm{q}} \mathrm{v}_{\mathrm{pqikr}}+\sum_{\mathrm{j}} \sum_{\mathrm{k}} \sum_{\mathrm{r}} \mathrm{T}_{\mathrm{jkr}} \sum_{\mathrm{p}} \sum_{\mathrm{q}} \mathrm{w}_{\mathrm{pqjkr}}\right) \\
& \sum_{\mathrm{p}} \sum_{\mathrm{q}} \sum_{\mathrm{k}} \mathrm{ED}_{\mathrm{pqk}}- \\
& \sum_{\mathrm{j}} \delta_{\mathrm{j}} \psi_{\mathrm{j}} \quad-
\end{aligned}
$$

Subject to

$$
\begin{array}{ll}
\sum_{q} \sum_{r} \sum_{j} x_{p q i j r}+\sum_{q} \sum_{r} \sum_{k} v_{p q i k r} \leq C_{p i}, & \forall i, p \\
\sum_{p} \sum_{q} \sum_{r} \sum_{j} x_{p q i j r}+\sum_{p} \sum_{q} \sum_{r} \sum_{k} v_{p q i k r} \leq C_{i} & \\
\sum_{p} \sum_{r} \sum_{j} x_{p q i j r}+\sum_{p} \sum_{r} \sum_{k} v_{p q i k r} \leq Z_{q i}, & \forall i \\
\sum_{p} \sum_{q} \sum_{j} x_{p q i j r}+\sum_{p} \sum_{q} \sum_{k} v_{p q i k r} \leq S_{r i}, & \forall \mathrm{i}, \mathrm{p}
\end{array}
$$




$$
\begin{array}{lr}
\sum_{j} \sum_{r} w_{p q j k r}+\sum_{i} \sum_{r} v_{p q i k r} \leq D_{k p q}^{M a x} & \forall \mathrm{k}, \mathrm{p}, \mathrm{q} \\
\sum_{j} \sum_{r} w_{p q j k r}+\sum_{i} \sum_{r} v_{p q i k r} \geq D_{k p q}^{M i n} & \forall \mathrm{k}, \mathrm{p}, \mathrm{q} \\
\sum_{i} \sum_{r} x_{p q i j r}=\sum_{k} \sum_{r} w_{p q j k r} & \forall \mathrm{j}, \mathrm{p}, \mathrm{q} \\
\sum_{p} \sum_{q} \sum_{k} \sum_{r} w_{p q j k r} \leq M \delta_{j} & \forall \mathrm{j}
\end{array}
$$

\subsection{Model Interpretation}

Equation (1) expresses the goal of the profit maximization problem which is a function of the revenue from the customers, production costs, packaging costs, transport costs, handling costs at warehouses, excise duty at retailers, and setup costs or rental costs at warehouses. Equation (2) ensures that the quantity of supply of any product type for any plant, warehouse and customer demand location combination does not exceed the production capacity of this product type at that plant. Equation (3) ensures that the quantity of supply of all type of products for any plant, warehouse and customer demand location combination does not exceed the production capacity of the plant. Equation (4) ensures that the quantity of supply of a product with a given type of packaging for any plant, warehouse and customer demand location combination does not exceed the packaging type capacity at that plant. Equation (5) ensures that quantity of supply of any product for any plant, warehouse and customer demand location combination by a given mode of transport does not exceed the transport capacity allocated for that mode of transport. Equation (6) ensures that the quantity of supply of a product type with a given type of packaging for any plant, warehouse and customer demand location combination does not exceed the maximum demand for this product with this given packaging type at that customer demand location. Equation (7) ensures that the total of supply of a product type with a given type of packaging for any plant, warehouse and customer demand location combination fulfills the minimum supply of the product for the given packaging type as promised for this customer demand location. This ensures the attainment of a minimum service level agreement as signed with the customer. Equation (8) ensures that no inventory is stored at warehouses on a continual basis and warehouses are used as a transshipment point. Equation (9) ensures that decision variable $\delta_{j}$ $=1$ if warehouse $\mathrm{w}_{\mathrm{j}}$ is used as a transshipment point.

\section{IMPLEMENTATION AND ANALYSIS}

\subsection{Numerical Examples and Illustrations}

In this subsection, I will discuss the two numerical examples used to illustrate the proposed model. The examples are based on supply chains with three stages consisting of production units, warehouses and customer demand locations. The model is solved both for two and three product types. A summary of the results obtained for these different problem sizes are shown in Table 4.1 below.

Table 1: Problem cases

\begin{tabular}{|l|l|l|l|l|l|l|l|l|l|l|}
\hline Case & $\begin{array}{l}\text { \# } \\
\text { Plant }\end{array}$ & $\begin{array}{l}\text { \# Ware- } \\
\text { house }\end{array}$ & $\begin{array}{l}\text { \# Trans } \\
\text { Mode }\end{array}$ & $\begin{array}{l}\text { \# Item } \\
\text { type }\end{array}$ & $\begin{array}{l}\text { \# Pack- } \\
\text { aging } \\
\text { Type }\end{array}$ & \# Location & \# Constraint & $\begin{array}{l}\text { \# Decision } \\
\text { Variable }\end{array}$ & $\begin{array}{l}\text { \# Itera- } \\
\text { tion }\end{array}$ & $\begin{array}{l}\text { \# Ware- } \\
\text { house } \\
\text { Located }\end{array}$ \\
\hline 1 & 2 & 2 & 2 & 2 & 2 & 10 & 104 & 354 & 56 & 0 \\
\hline 2 & 3 & 5 & 2 & 3 & 2 & 50 & 659 & 4,985 & 436 & 4 \\
\hline 3 & 9 & 318 & 2 & 2 & 4 & 4,783 & 16,811 & 141,068 & 10312 & 150 \\
\hline
\end{tabular}


From the table it is clear that the integrated production and distribution planning model is able to solve problems of various sizes. Cases 1 and 2 are examples of optimization problems, whereas Case 3 is a real problem involving a cement manufacturing company.

Case 1 optimizes the production and distribution plan for 2 plants with a 10 location supply chain with 2 types of products, 2 types of packaging, and 2 types of transport modes. It takes 56 iterations to produce the optmimum solution. It does not prescribe any warehouse as this is a simple supply chain. Case 2 is an illustrative exmple for a relatively more complex supply chain. The optimum solution prescribes subcontracting 4 warehouses to fullfill demand. Case 3 involves 9 plants and 4,783 customer demand locations with two products and two modes of transport, and takes 10,312 iterations to produce its optimum solution and ends up recommending the subcontracting of 150 warehouses. So the proposed model recommends warehouses as transhipment points for complex supply chains whereas it does not for a simple supply chain.

Case 3 will be discussed in detail in the next subsection. All of the three cases were solved using SAS OR software (SAS Institute Inc. (2011) and the time taken for all of them was less than 2 minutes. OPTMODEL, an algebraic modeling language, was used by the SAS/OR software to solve the problems. The OPTMODEL procedure allows efficient programming of large optimization problems. It uses the branch and cut algorithm to solve the proposed MIP optimization model.

\subsection{Case study}

The proposed model was implemented for a cement manufacturing organization in India which has 9 manufacturing plants spread across the country serving customers all over the country. Production capacity data for each of the plants was collected from the plant operation managers. The transportation cost, transportation capacity and demand data were collected from the supply chain planning managers. They also shared the data for minimum supply agreements and the selling price at different customer locations. This cement manufacturer produces two types of cement called OPC and PPC which are sold in the market with four types of packaging. In an emerging market like India, there are two types of demand for cement: bulk and retail. The cement manufacturing industry serves the demands of dif- ferent geographical locations and has contracts with dealers to serve end customers. Dealers are the customers of this manufacturing company. They also serve the bulk demands of the construction industry. Manufacturing plants are set up near sources of raw materials. The rate of demand is not constant over time in each region as infrastructure construction activities move to different locations over time. The proposed model which integrates production, warehouse location and distribution planning is ideal for scenarios where the rate of demand is not constant in a region. The proposed model allows the manufacturer to set up or subcontract warehouses to act as transshipment points and serve the demands of customers who are located very far away from the manufacturing plants. The model has also integrated the minimum demand fulfillment agreement and does not differentiate between bulk demand and retail demand because the model has been formulated as a profit maximization model.

How best to configure cement production, distribution and warehouse planning has been solved using real data collected from this manufacturing organization. There are 4,783 demand locations and 9 cement plants to serve demand. 318 is the number of warehouses available to be used as transshipment points. Railways and roads are two of the transport modes. In reality every plant is connected to every warehouse and demand location, but transport cost data is not available for some of the routes. In the baseline scenario, the total demand is 781,321 tons and the objective value is $2,861,932,772$ INR. $0.02 \%$ of demand is not fulfilled due to lack of transportation route data. The total number of iterations required to solve the problem was 10,312 using a four thread 32GB RAM machine. The optimized solution recommends 150 warehouses. The overall utilization rate is $67 \%$, and there are two plants which are highly underutilized $(<=30 \%)$, and four plants with high utilization $(>80 \%)$.

The results obtained using real data from this manufacturing company are in sync with the geographical locations of the plant, warehouse and customer locations. The nearer customer locations are supplied directly from the plant, whereas customer locations that are farther away get supplied by the warehouses. The warehouses are supplied by various plants. The discussion of these results with plant managers also suggests a reduction in the cost components. The results also suggest that the optimal number of warehouses required is substantially smaller than the number of warehouses operating currently. 
Table 2 Objective value for different levels of demand

\begin{tabular}{|l|l|l|l|l|}
\hline Iteration & \%Profit & \%Demand & Overall Plant Utilization & \# Warehouses \\
\hline $.80 *$ Baseline & $79.99 \%$ & $99.980 \%$ & $53 \%$ & 147 \\
\hline $.90 *$ Baseline & $89.93 \%$ & $99.980 \%$ & $60 \%$ & 148 \\
\hline Baseline Demand & $100.00 \%$ & $99.980 \%$ & $67 \%$ & 150 \\
\hline $1.10 *$ Baseline & $109.85 \%$ & $99.979 \%$ & $73 \%$ & 153 \\
\hline $1.20 *$ Baseline & $119.55 \%$ & $99.980 \%$ & $80 \%$ & 154 \\
\hline $1.30 *$ Baseline & $128.84 \%$ & $99.980 \%$ & $87 \%$ & 153 \\
\hline
\end{tabular}

\subsection{Sensitivity analysis}

In a given process, a utilization rate of more than $80 \%$ strains the entire process. Table 2 shows the objective value for different levels of demand in proportion to baseline demand, and Table 3 shows plant utilization at different levels of demand. Approximately $100 \%$ of demand is fulfilled in all of the levels considered. Though the overall utilization rate ranges from $53 \%$ to $87 \%$, plant $\mathrm{P} 4$ is always $100 \%$ utilized for economic reasons, whereas plants P7 and P9 are the least utilized in every case.

Table 3 Utilization for different levels of demand

\begin{tabular}{|l|l|l|l|l|l|l|l|l|l|}
\hline Scenario/Plants & P1 & P2 & P3 & P4 & P5 & P6 & P7 & P8 & P9 \\
\hline $.80 *$ Baseline & $61 \%$ & $83 \%$ & $64 \%$ & $100 \%$ & $45 \%$ & $42 \%$ & $17 \%$ & $62 \%$ & $24 \%$ \\
\hline $.90 *$ Baseline & $69 \%$ & $100 \%$ & $83 \%$ & $100 \%$ & $52 \%$ & $48 \%$ & $19 \%$ & $70 \%$ & $27 \%$ \\
\hline Baseline Demand & $83 \%$ & $100 \%$ & $100 \%$ & $100 \%$ & $60 \%$ & $53 \%$ & $21 \%$ & $80 \%$ & $30 \%$ \\
\hline $1.10 *$ Baseline & $100 \%$ & $100 \%$ & $100 \%$ & $100 \%$ & $89 \%$ & $59 \%$ & $24 \%$ & $92 \%$ & $33 \%$ \\
\hline $1.20 *$ Baseline & $100 \%$ & $100 \%$ & $100 \%$ & $100 \%$ & $100 \%$ & $77 \%$ & $34 \%$ & $100 \%$ & $43 \%$ \\
\hline $1.30 *$ Baseline & $100 \%$ & $100 \%$ & $100 \%$ & $100 \%$ & $100 \%$ & $99 \%$ & $47 \%$ & $100 \%$ & $48 \%$ \\
\hline
\end{tabular}

These observations have been used to create different scenarios for production capacities which are applicable to the manufacturing industry. Solutions to these scenarios are helpful in production planning and affect profitability in different situations. The objective value and utilization of each of the plants in these scenarios are presented in Tables 4 and 5 . The production capacity scenarios are discussed below:

a. Scenario: All 9 of the plants are operating at $90 \%$ of production capacity. This is analogous to the situation that occurs when plants undergo periodic maintenance activities.

b. Scenario: Plant P7 is closed. The utilization of plant P7 is only $21 \%$ for the baseline demand case. Management may want to close this plant.

c. Scenario: Plants P7 \& P9 are closed. Similar to P7, plant P9 is also highly underutilized.
Management may decide to close both of these plants.

d. Scenario: Plants P7 \& P9 are closed, and plants P2, P3 \& P4 are operating at 90\% of production capacity. The remaining plants are operating at $100 \%$ capacity. This is analogous to the situation that occurs when P7 and P9 are closed and $100 \%$ of the utilized plants are available with $90 \%$ capacity occurring due to maintenance activities.

e. Scenario: Plant P4 is closed. Plant P4 is the most economical plant, and is $100 \%$ utilized even when demand is at $80 \%$. This plant will have to be shut down for maintenance due to a critical breakdown situation.

f. Scenario: Plant P4 is closed and plants P1, P2, P3, P5 \& P8 are operating at 90\% due to maintenance activities. 
Table 4 Utilization for different production capacity

\begin{tabular}{|l|l|l|l|l|l|l|l|}
\hline Plant Code & $\begin{array}{l}\text { Baseline } \\
\text { Utilization }\end{array}$ & a) Scenario & b) Scenario & c) Scenario & d) Scenario & e) Scenario & f) Scenario \\
\hline P1 & $83 \%$ & $90 \%$ & $88 \%$ & $91 \%$ & $96 \%$ & $100 \%$ & $90 \%$ \\
\hline P2 & $100 \%$ & $90 \%$ & $100 \%$ & $100 \%$ & $90 \%$ & $100 \%$ & $90 \%$ \\
\hline P3 & $100 \%$ & $90 \%$ & $100 \%$ & $100 \%$ & $90 \%$ & $100 \%$ & $90 \%$ \\
\hline P4 & $100 \%$ & $90 \%$ & $100 \%$ & $100 \%$ & $90 \%$ & & \\
\hline P5 & $60 \%$ & $84 \%$ & $60 \%$ & $75 \%$ & $100 \%$ & $100 \%$ & $90 \%$ \\
\hline P6 & $53 \%$ & $54 \%$ & $61 \%$ & $69 \%$ & $72 \%$ & $77 \%$ & $90 \%$ \\
\hline P7 & $21 \%$ & $23 \%$ & & & & $34 \%$ & $45 \%$ \\
\hline P8 & $80 \%$ & $84 \%$ & $80 \%$ & $81 \%$ & $85 \%$ & $100 \%$ & $90 \%$ \\
\hline P9 & $30 \%$ & $30 \%$ & $40 \%$ & & & $35 \%$ & $37 \%$ \\
\hline $\begin{array}{l}\text { Objective } \\
\text { Value }\end{array}$ & $100 \%$ & $99 \%$ & $98 \%$ & $98 \%$ & $100 \%$ & $96 \%$ & $95 \%$ \\
\hline
\end{tabular}

Table 5 Objective value for different production capacities

\begin{tabular}{|l|l|l|}
\hline Scenarios & Objective Value as \% of Baseline Objective & \# Warehouses \\
\hline a) Scenario & $98.79 \%$ & 145 \\
\hline b) Scenario & $97.78 \%$ & 144 \\
\hline c) Scenario & $97.63 \%$ & 143 \\
\hline d) Scenario & $99.87 \%$ & 152 \\
\hline e) Scenario & $95.79 \%$ & 150 \\
\hline f) Scenario & $95.07 \%$ & 150 \\
\hline
\end{tabular}

\section{THE OPTMODEL PROCEDURE IN SAS /OR}

The data manipulation ability of SAS software makes it easy to handle problems of any size. In the implementation of Case 3 in which real data is used, plant managers know that all plants are not connected by usable transportation routes to the destination points (customer locations or warehouses) hence all possible combinations are not present in the data used for transportation costs. Also it is known from the expected demand data that all customer locations will not have demand for all types of products. In such problems the number of constraint and decision variables cannot be correctly enumerated using permutations and combinations. Considering all the combinations in the programming, some of which are infeasible, also reduces its efficiency as it does not add any value to the objective function. These kinds of challenges in real problems can be very easily programmed using SAS OPTMODE to solve integrated optimization problems. The OPTMODEL procedure is discussed briefly in the next subsection.

\section{CONCLUSIONS AND FUTURE WORK}

The model proposed in this study determines the optimal integrated production, warehouse location and distribution planning as part of a profit maximization problem. Other studies in the literature have formulated the integrated optimization problem as a cost minimization problem. The analysis of solutions for a large real supply chain problem involving a cement manufacturing company shows that complex supply chains can be modeled and have good performance. This study presents a model that enables decision makers to simultaneously optimize product and customer allocations and warehouse locations within a multi-plant, multi-product and multi-route supply chain system. The various scenarios discussed in terms of sensitivity analysis are useful in understanding what leverages profitability and redundant production capacity. These scenarios are highly relevant in a manufacturing industry. In the electronics, apparel and food processing industries, where a large variety of products is produced 
and transported to many market locations, the proposed integrated production and distribution planning model is highly relevant. The model is also useful for planning annual maintenance work or temporary plant shutdowns. In the presented approach demand is deterministic. This can be forecasted periodically using historical sales data, and then it can be used as input into proposed models of supply chain optimization. Future research dealing with stochastic demand and the lead time in the model for perishable items would be useful. The proposed model can also be extended to consider the penalties that result from half truck loads and routing decisions in the integrated model.

\section{ACKNOWLEDGEMENTS}

The author would like to acknowledge the contributions of the anonymous manufacturing company in the form of real data and managerial input.

\section{REFERENCES}

Arntzen, B. C., Brown, G. G., Harrison, T. P., \& Trafton, L. L. (1995). Global supply chain management at Digital Equipment Corporation. Interfaces, 25(1), 69-93.

Bashiri, M., Badri H., \& Talebi J.( 2012). A new approach to tactical and strategic planning in production-distribution networks. Applied Mathematical Modelling, 36(4), 1703-1717. doi:10.1016/j.apm.2011.09.018

Canel, C., \& Khumawala, B. M. (1997). Multi-period international facilities location: An algorithm and application. International Journal of Production Research, 35(7), 1891-1910. doi:10.1080/002075497194976

Canel, C., \& Khumawala, B. M. (2001). International facilities location: A heuristic procedure for the dynamic incapacitated problem. International Journal of Production Research, 39(17), 3975-4000.

Camm, J. D., Chorman, T. E., Dill, F. A., Evans, J. R., Sweeney, D. J., \& Wegryn, G. W. (1997). Blending OR/MS, judgment, and GIS: Restructuring P\&G's supply chain. Interfaces, 27(1), 128-142. doi:10.1287/inte.27.1.128

Chandra, P. A. (1993). A dynamic distribution model with warehouse and customer replenishment requirements. Journal of the Operational Research Society, 44(7), 681-692. doi:10.2307/2584042

Chandra, P., \& Fisher, M. L. (1994). Coordination of production and distribution planning. European Journal of Operational Research, 72(3), 503-517. doi:10.1016/0377-2217(94)90419-7
Cóccola, M. E., Zamarripa, M., Méndez, C. A., \& Espuña A. (2013). Toward integrated production and distribution management in multi-echelon supply chains. Computers and Chemical Engineering, 57, 78-94. doi:10.1016/j.compchemeng.2013.01.004

Dasci, A., \& Verter, V., (2001). A continuous model for production-distribution system design. European Journal of Operational Research, 129(2), 287-298. doi:10.1016/S03772217(00)00226-5

Dhaenens-Flipo, C., \& Finke, G., (2001). An integrated model for an industrial-distribution problem. IIE Transactions, 33(9), 705-715. doi:10.1023/A:1010937614432

Dror, M., \& Ball M. (1987). Inventory routing: Reduction from an annual to a short period. Naval Research Logistics, 34, 891-905. doi:10.1002/1520-6750(198712)34:6<891::aidnav3220340613>3.0.co;2-j

Erengüç, S. S., Simpson, N. C., \& Vakharia, A. J. (1999). Integrated production/distribution planning in supply chains: An invited review. European Journal of Operational Research, 115(2), 219-236.

Fawcett, S. E., \& Magnan, G. M. (2002). The rhetoric and reality of supply chain integration. International Journal of Physical Distribution and Logistics Management, 32(5), 339-361. doi:10.1108/09600030210436222

Fumero, F., \& Vercellis, C. (1991). Synchronized development of production, inventory, and distribution schedules. Transportation Science, 33(3), 330-340. doi:10.1287/trsc.33.3.330

Ganeshan, R., \& Harrison, T. P. (1995). An introduction to supply chain management. Retrieved from http://lcm.csa.iisc.ernet. in/scm/supply_chain_intro. html.

Garcia, J. M., Sánchez, L. S., Guerrero, F., Calle, M., \& Smith. K. (2004). Production and vehicle scheduling for ready-mix operations. Computers \& Industrial Engineering, 46(4), 803826. doi:10.1016/j.cie.2004.05.011

Jolayemi, J. K. (2010). Optimum production-distribution and transportation planning in three-stage supply chains. International Journal of Business and Management, 5(12), 29-40. doi:10.5539/ijbm.v5n12p29

Kaur, A., Kanda, A., \& Deshmukh, S. G. (2006). A graph theoretic approach for supply chain coordination. International Journal of Logistics Systems and Management, 2(4), 321-341. doi:10.1504/IJLSM.2006.010379

Kumanan, S., Venkatesan, S. P., \& Kumar, J. P., (2007). Optimisation of supply chain logistics network using random search techniques. International Journal of Logistics Systems and Management, 3(2), 252-266. doi:10.1504/IJLSM.2007.011824

Larbi, E. A. S., Bekrar, A., Trentesaux, D., \& Beldjilali, B. (2012). Multi-stage optimization in supply chain: an industrial case study. Paper presented at 9th International Conference of Modelling, Optimization and Simulation, Bordeaux France.

Lei, L., Liu, S, Ruszczynski, A, \& Park, S., (2006). On the integrated production, inventory, and distribution routing problem. IIE Transactions, 38(11), 955-970.

Lodree, E., Jang, W., \& Klein, C. M. (2004). Minimizing response time in a two-stage supply chain system with 
variable lead time and stochastic demand. International Journal of Production Research, 42(11), 2263-2278. doi:10.1080/0020754042000197676

Maleki, M., \& Cruz-Machado, V. (2013). A review on supply chain integration: Vertical and functional perspective and integration models. Economics and Management, 18(2), 340350. doi:10.5755/j01.em.18.2.2968

Patel, M. H., Wei, W., Dessouky, Y., Hao, Z., \& Pasakdee, R. (2009). Modeling and solving an integrated supply chain system. International Journal of Industrial Engineering, 16(1), 13-22.

Rong, A., Akkerman, R., \& Grunow, M. (2011). An optimization approach for managing fresh food quality throughout the supply chain. International Journal of Production Economics, 131(1), 421-429. doi:10.1016/j.ijpe.2009.11.026

SAS Institute Inc. (2011) SAS/OR® 9.3 User's Guide: Mathematical Programming. Cary, NC.
Silva, C. A., Faria, J. M., Abrantes, P., Sous, a J. M. C., Surico, M., \& Naso, D. (2005). Concrete delivery using a combination of GA and ACO. Proceedings of the 44th IEEE conference on decision and control, and the European control conference, 7633-7638.

Sabri, E. H., \& Beamon, B. M. (2000). A multi-objective approach to simultaneous strategic and operational planning in supply chain design. Omega, 28(5), 581-598. doi:10.1016/S03050483(99)00080-8

Tang, Z., Goetschalckx, M., \& McGinnis, L. (2013). Modelingbased design of strategic supply chain networks for aircraft manufacturing. Procedia Computer Science, 16, 611-620. doi:10.1016/j.procs.2013.01.064

Yu, V. F., Normasari, N. M. E, \& Luong, H. T. (2015). Integrated location-production-distribution planning in a multiproducts supply chain network design model. Mathematical Problems in Engineering, 2015, 1-13. doi:10.1155/2015/473172 